The calculation procedure predicts closely the load behaviour of a structure post-strengthened with a pretensioned CFRP laminate.

Since the CFRP laminate has no plastic deformation reserve the highest flexural resistance of a strengthened section is reached when laminate failure occurs simultaneously with the yield of the steel and before the concrete fails.

The type of failure is strongly influenced by the laminate cross-section and the tensioning force.

Tension and deformation calculations may be carried out with conventional methods. Test results on realistic beams confirm the validity of the classical assumptions.

Pretensioning reduces the danger of peeling off, mentioned above for non-pretensioned laminates.

The total sum of the crack widths is influenced even more favourably than with non-pretensioned laminates.

The excellent fatigue behaviour exceeds all expectations.

\section{APPLICATIONS IN BRIDGE AND BUILDING CONSTRUCTION}

Since 1991 there have been many applications of this new technique in Switzerland. In 1991 the first bridge, the Ibach Bridge near Lucerne [4], in 1992 the covered wooden bridge in Sins [4], and the City Hall in Gossau, St. Gall [4], were renovated with this method. In 1993 there were already more than 30 new cases. Currently, there is every week at least one new application of the CFRP sheet bonding technique in Switzerland.

\section{OUTLOOK}

Based on the research and development work at EMPA the application of CFRP laminates is already routine for several companies in Switzerland. In the USA, where the market potential is actually the greatest, things have not yet advanced quite so far. Nevertheless, the American government is making great efforts, above all in the Defense Conversion Program, to promote high performance fibre composites, particularly carbon fibres for civil engineering applications. Within the framework of the 'Advanced Materials Bridge Initiative' [5] the Federal Government is investing $\$ 200$ million to stimulate this program. On the one hand, this involves rehabilitation work as described in this paper and on the other hand futuristic projects as already sketched out by Meier [6]. In the author's opinion fibre composites have excellent chances in specific civil engineering applications as described here. However, even in the future they will not replace classical materials such as steel, concrete and wood, but rather supplement them as called for.

\section{REFERENCES}

1. Meier, U., 'Brückensanierungen mit HochleistungsFaserverbundwerkstoffen', Mater. Technik 15 (1987) $125-128$.

2. Kaiser, H. P., 'Bewehren von Stahlbeton mit kohlenstoffaserverstärkten Epoxidharzen, Dissertation, ETH No. 8918 (Eidgenössische Technische Hochschule, Zurich, 1989).

3. Deuring, M., 'Verstärken von Stahlbeton mit gespannten Faserverbundwerkstoffen', EMPA-Bericht No. 224 (Eidgenössische Materialprüfungs- und Forschungsanstalt, EMPA, Dübendorf, 1993).

4. Meier, U., Deuring, M., Meier, H. and Schwegler, G., 'Strengthening of structures with advanced composites', in 'Alternative Materials for the Reinforcement and Prestressing of Concrete', edited by John L. Clarke (Chapman \& Hall, 1993) pp. 153-171.

5. National Technology Policy: Recommendations \& Initiatives, Adv. Composites (Jan./Feb. 1993) p. 15.

6. Meier, U., 'Proposal for a carbon fibre reinforced composite bridge across the Strait of Gibraltar at its narrowest site', Proc. Instn Mech. Engrs 201 (B2) (1987) 73-78.

\title{
Fibre reinforced plastic splices for joints in timber structures
}

\section{A. ULRICH MEIERHOFER \\ EMPA Department Wood}

\section{INNOVATIONS FOR TIMBER STRUCTURES}

Fibre reinforced plastic (FRP), where applied at all in timber construction, has been merely for repair and secondary functions. Recentiy, after an extended period of development and research, a new system has been introduced in the US market which should provide for the economical reinforcement of glulam beams with FRP [1]. The application of FRPs to connections between structural timber parts is the goal of a research and development project of the EMPA Wood Department.
For timber structures, the design of the joints plays a decisive role and poses a challenge for innovative trials, especially regarding the transfer of tensile forces.

\section{TENSILE JOINT}

Preliminary tensile tests with small FRP-spliced specimens were performed to determine the influence of various parameters like type of resin, thickness of glueline, or length of splice of FRP-lamination and to gather experience with the workability and the adhesion of the 


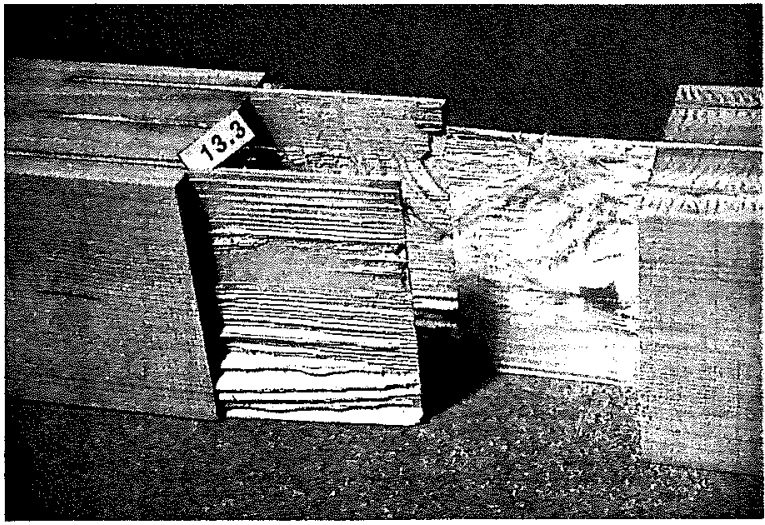

Fig. 1 Breaking zone of a tensile test specimen with 3 glass fibre reinforced plastic plates. No fracture within the glueline is evident.

glues to the connecting parts [2]. At this stage mainly carbon fibre had been used as a reinforcing material.

At the next stage a considerable number of tensile tests were performed using larger size glued laminated specimens (cross-section up to $110 \mathrm{~mm} \times 110 \mathrm{~mm}$ ) having, in most cases, splices with glass fibre reinforced plastic plates (Fig. 1) [3]. Similar test parameters were used: type of resin, length of connecting plate, number and spacing of the plates, stiffness $(E \times \mathrm{A})$ of plates, reinforcement of the cross-section (to compensate for transverse tension), shape of grooves for the plates, climate exposure, etc.

In addition to the tensile tests a number of bending tests were performed using beams with a span of $2.8 \mathrm{~m}$ and a cross-section of $120 \mathrm{~mm} \times 180 \mathrm{~mm}$. A long term creep test with such a specimen is still under way.

\section{TEST RESULTS}

The investigations provided numerous results of a quantitative nature, especially strength and stiffness values as well as of a qualitative nature, regarding the suitability of materials, which were basically glues and FRPs. Problems of workability, which plays a decisive role for the quality of the splice, were clarified also.

The bond between the epoxy resin and the wood, as expected, provided no problems. Satisfactory adhesion to the surface of the FRP-laminations, however, was not easy to achieve. The quality of the filling of the joints depends greatly on the viscosity of the resin which, in turn, influences the volumetric shrinkage and through this the quality and strength of the filling.

With all three splice lengths $(=2 \times$ groove depths in the wood) tested, namely $100 \mathrm{~mm}, 150 \mathrm{~mm}$ and $200 \mathrm{~mm}$, considerable tensile strengths were achieved in the joints. The joint strength tends to be higher with increasing splice length, but the average shear stress at failure is clearly smaller with the long splices, due to the characteristics of the shear stress distribution along the joint. The stress distribution, together with transverse tensile forces and the shear stress concentration at the joint govern the failure mechanism. The stress concentration may be decreased by using a stiffer laminate, which thereby increases the joint strength. The stress concentration may be reduced also by enlarging the width of the groove in the wood near the joint. A chamfer of $15 \mathrm{~mm}$ length and $1 \mathrm{~mm}$ width enhances the strength by as much as $25 \%$ ! Increased strength was obtained also by reinforcing the specimens with beech plywood to absorb the transverse tensile forces. Another efficient method for reducing the transverse tensile forces and thereby increase the strength of the joint is to augment the number of the splice plates.

\section{HIGH STRENGTH, HIGH STIFFNESS}

For more than one year nine specimens were exposed to climatic influences: high humidity $\left(20^{\circ} \mathrm{C} / 95 \% \mathrm{RH}\right)$, changing humidity $\left(20^{\circ} \mathrm{C} / 95 \% \mathrm{RF} \leftrightarrow 20^{\circ} \mathrm{C} / 35 \% \mathrm{RH}\right)$ and outside (under shelter). The reduction of strength by these treatments turned out to be minor $(\approx 15 \%)$. In the bending tests the MOR reached values between $30 \mathrm{~N} \mathrm{~mm}^{-2}$ and $34 \mathrm{~N} \mathrm{~mm}^{-2}$ (referring to the gross cross-section). The increase in the deflection of the beams due to the splice was merely $6 \%-12 \%$, i.e., the stiffness of the splice proved to be remarkable. In a long-term creep test a beam having a maximum bending stress of $23 \mathrm{~N} \mathrm{~mm}^{-2}$ increased its deflection within one year for about $20 \%$, showing a gradual stabilization of the creep movement.

The results of the investigations obtained so far demonstrate the feasibility of FRP-splices for joints in timber structures. The strength and stiffness values of the splices are very promising. More research is needed, however, to deepen our understanding of the behaviour of this type of joint and to clarify the influence of some more parameters like, for example, the differential expansion between wood and FRP (due to shrinking, swelling or temperature effects).

\section{REFERENCES}

1. Tingley, D. A., 'Wood and wood composite design using high-strength fibre-reinforced-plastic (FiRP ${ }^{\text {TM }}$ Panel) with special emphasis on glued laminated beam bridges', personal communication.

2. Timmermann, K. and Meierhofer, U. A., 'Fibre reinforced plastics in timber structures. Investigations and developments. Part II: Preliminary tensile tests with small specimens with FRP-spliced joints'. Research and progress report 115/26 (EMPA Wood Department, 1992). In German with English summary.

3. Idem, 'Fibre reinforced plastics in timber structures. Investigations and developments. Part III: Tensile and bending tests with glued laminated specimens. Research and progress report 115/32 (EMPA Wood Department, 1994). In German with English summary. 